\title{
SUPPLEMENTARY INFORMATION \\ IN DEFENSE OF MURBURN EXPLANATION FOR AEROBIC RESPIRATION
}

Kelath Murali Manoj*

Satyamjayatu: The Science \& Ethics Foundation, Snehatheeram, Kulappully, Kerala, India

\section{Contents}

Item 1: Lack of consensus regarding proton pumps (1-9)

Item 2: False attributions on lack of citations (10-11)

Item 3: False attributions on lack of literature back-up on reaction energetics (11)

Item 4: False attributions on lack of literature back-up on $K_{d}$ of Complex V (12)

Item 1: How six decades of chemiosmosis has sent scientists on vain consensus seeking exercises and not given oxygen its due!

Mitchell said that Comp. IV is not a proton pump!

\section{CYTOCHROME $c$ OXIDASE IS NOT A PROTON PUMP}

Jennifer MOYLE and Peter MITCHELL

Glynn Research Laboratories, Bodmin, Cornwall, PL30 4AU, Engiand

Received 23 January 1978

\section{Introduction}

Mitchell postulated that cytochrome $c$ oxidase is plugged through the coupling membrane of mitochondria and bacteria so that the reduction of $\mathrm{O}_{2}$ to $2 \mathrm{H}_{2} \mathrm{O}$ involves the translocation of $4 \mathrm{e}^{-}$from cytochrome $c$ at the outer surface of the membrane to

$4 \mathrm{H}^{*}$ ions that enter the reaction domain from the inner aqueous phase [1]. As evidence for this putativ matter whether $\mathrm{O}_{2}$ or ferricyanide was used as oxidant [2] . As ferricyanide is impermeant and oxidises cytochrome $c$, bypassing cytochrome $c$ oxidase, we concluded that cytochrome $c$ oxidase does not act as a proton pump, but catalyses only the net translocation of electrons [3]. Work by Hinkle, Papa, Racker and others, using mitochondria, sonically-prepared mitochondrial vesicles and liposomes inlaid with cytochrome $c$ oxidase has greatly strength-

*Correspondence to: Dr Kelath Murali Manoj, Satyamjayatu: The Science \& Ethics Foundation, Snehatheeram, Kulappully, Shoranur-2 (PO), Kerala, India-679122

E-mail: satyamjayatu@yahoo.com (ORCID: 0000-0003-4515-994X) 
Nałęcz said Complex III is not a proton pump!

Journal of Bioenergetics and Biomembranes, Vol. 18, No. 1, 1986

\title{
MINI REVIEW
}

\section{Is There Sufficient Experimental Evidence to Consider the Mitochondrial Cytochrome $b c_{1}$ Complex a Proton Pump? Probably No. ${ }^{1}$}

\author{
Maciej J. Nałęcz ${ }^{2}$
}

Received October 8, 1985

Judy Hirst says Comp. I is a sodium pump!

\section{The dichotomy of complex I: A sodium ion pump or a proton pump}

\section{Judy Hirst*}

Medical Research Council, Dunn Human Nutrition Unit, Wellcome Trust/MRC Building, Hills Road, Cambridge CB2 2XY, United Kingdom

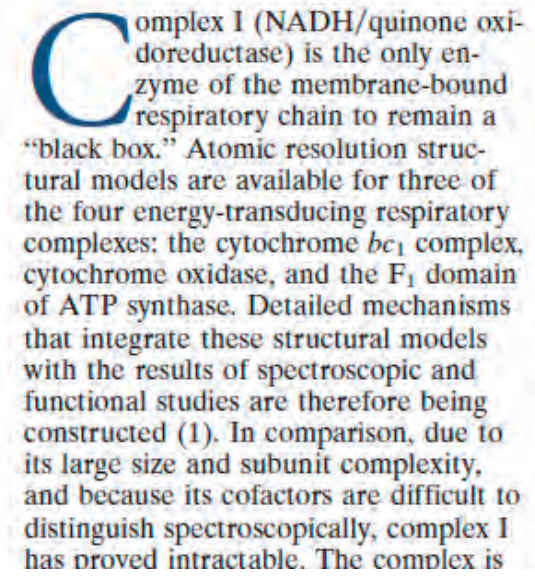

prise the simpler bacterial enzymes (9) and therefore are deemed sufficient for catalysis and energy transduction. The core subunit conservation and homology suggest that all complexes I operate by a common mechanism. However, if bovine complex I pumps four protons across the membrane for each NADH oxidized but complex I from $K$. pneumoniae pumps two sodium ions (10), then this conclusion must be questioned. These different cation specificities and stoichiometries have fundamental implications for our understanding of the mechanism of complex $I$ and its role in energy transduction and metabolism, and challenge the relevance of bacterial complexes I as models for the mamma- allow meaningful sequence comparisons to be drawn, and these may help to identify the cation-binding sites, A similar approach was employed successfully for ATP synthase (11): most ATP synthases use a proton motive force, but closely related examples that use a sodium ion motive force have been identified in bacteria such as Propionigenium modestum. A family of sodium ion/proton antiporters identified in alkaliphilic bacteria contain stretches of sequence similarity with the membrane-bound ND2, 4, and 5 (NuoN, -M, and -L) subunits of complex I $(12,13)$. On this basis, these subunits have been proposed to bind cations and to constitute a conforma- 


\section{A giant molecular proton pump: structure and mechanism of respiratory complex I}

\section{Leonid A. Sazanov}

Abstract | The mitochondrial respiratory chain, also known as the electron transport chain (ETC), is crucial to life, and energy production in the form of ATP is the main mitochondrial function. Three proton-translocating enzymes of the ETC, namely complexes I, III and IV, generate proton motive force, which in turn drives ATP synthase (complex V). The atomic structures and basic mechanisms of most respiratory complexes have previously been established, with the exception of complex I, the largest complex in the ETC. Recently, the crystal structure of the entire complex I was solved using a bacterial enzyme. The structure provided novel insights into the core architecture of the complex, the electron transfer and proton translocation pathways, as well as the mechanism that couples these two processes.

Voet's Biochemistry ratios (Comp. $I=4, \mathrm{CoQ}=4$, Comp. IV = 2)

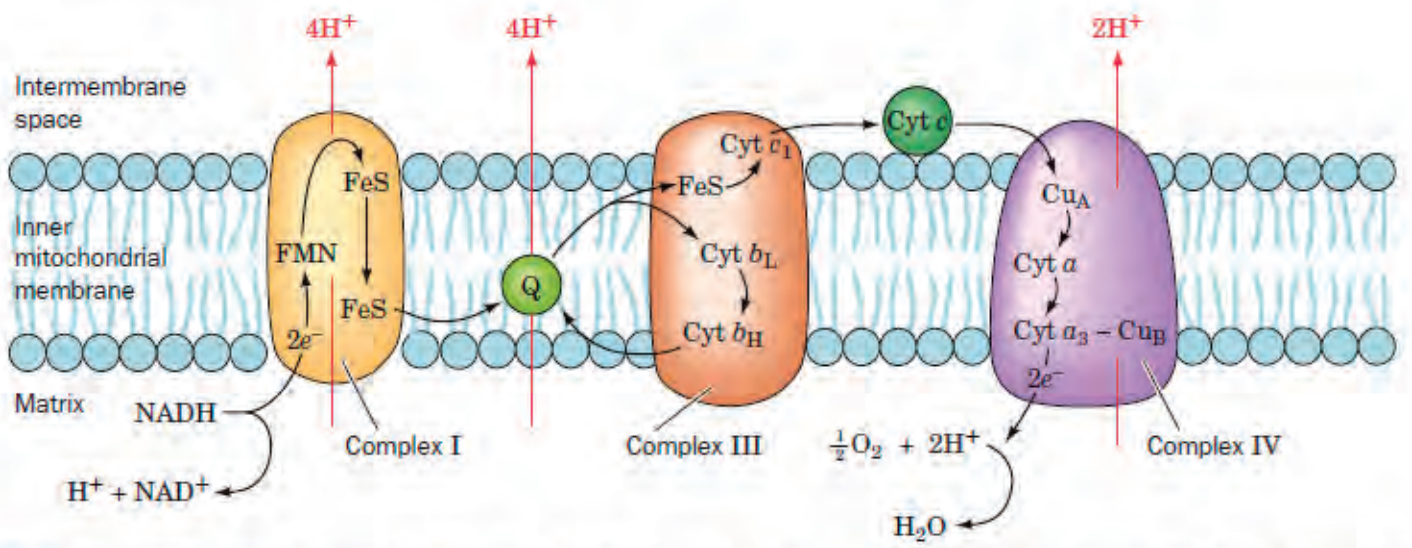

Figure 22-14 The mitochondrial electron-transport chain. The pathways of electron transfer (black) and proton pumping (red) are indicated. Electrons are transferred between Complexes 1 and III by membrane-soluble $\operatorname{CoQ}(\mathrm{Q})$ and between Complexes

III and IV by the peripheral membrane protein cytochrome $c$ (Cyt c). Complex II (not shown) transfers electrons from succinate to CoQ. $\$ 2$ see the Animated Figures 
Lehningers' Principles of Biochemistry ratios (Comp. I = 4, Comp. III = 4, Comp. IV =2)

(Same as Garret-Grisham's \& Stryer's textbooks)

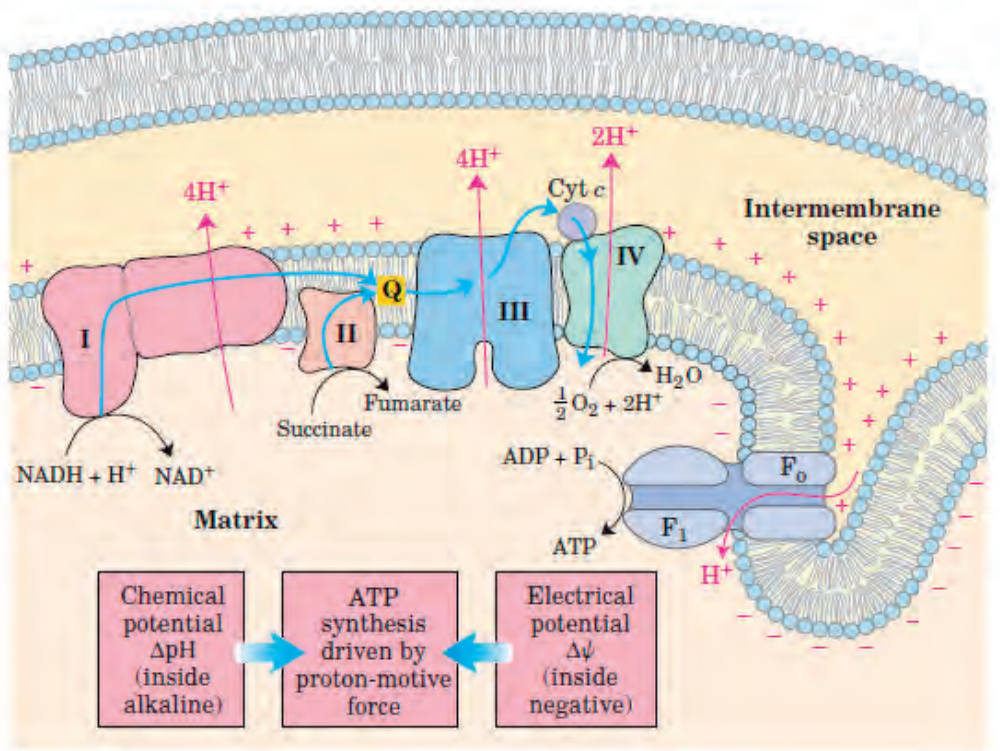

Metzler's Biochemistry ratios (Comp. I = 4, Comp. III = 4, Comp. IV = 4)

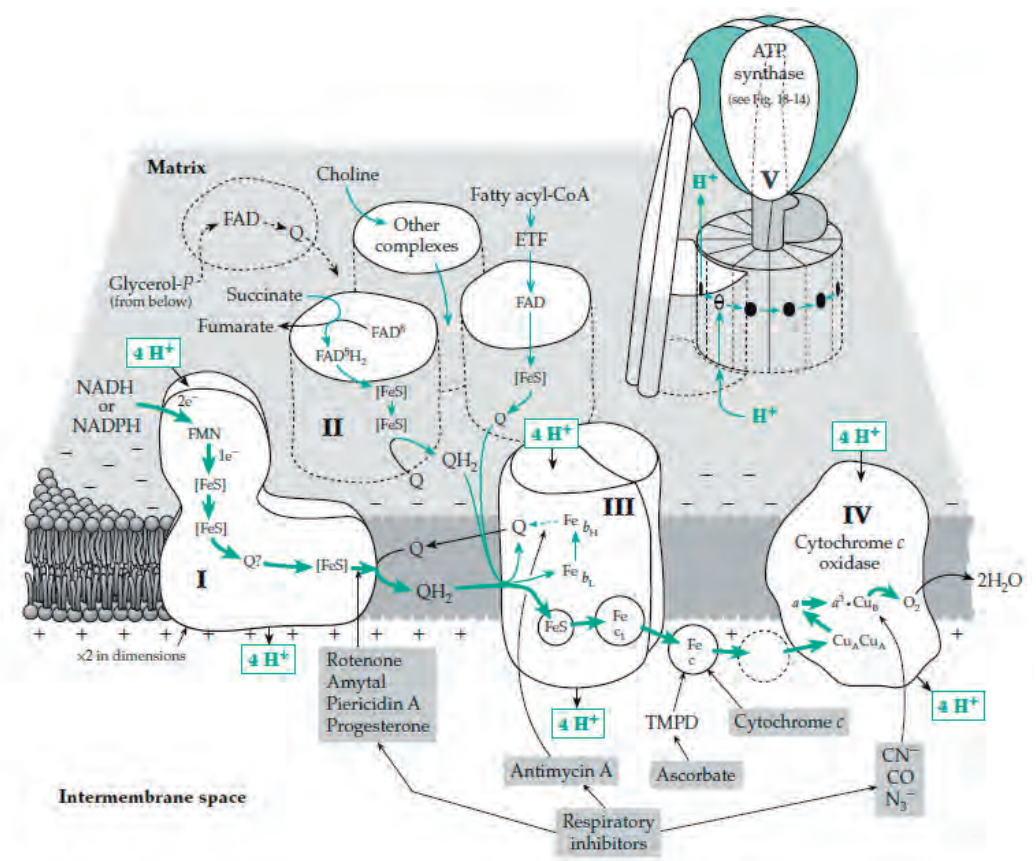

Figure 18-5 A current concept of the electron transport chain of mitochondria. Complexes I, III, and IV pass electrons from $\mathrm{NADH}$ or $\mathrm{NADPH}$ to $\mathrm{O}_{2}$, one NADH or two electrons reducing one $\mathrm{O}$ to $\mathrm{H}_{2} \mathrm{O}$. This electron transport is coupled to the transfer of about $12 \mathrm{H}^{+}$from the mitochondrial matrix to the intermembrane space. These protons flow back into the matrix through ATP synthase (V), four $\mathrm{H}^{+}$driving the synthesis of one ATP. Succinate, fatty acyl-CoA molecules, and other substrate are oxidized via complex II and similar complexes that reduce ubiquinone $\mathrm{Q}$, the reduced form $\mathrm{QH}_{2}$ carrying electrons to complex III. In some tissues of some organisms, glycerol phosphate is dehydrogenated by a complex that is accessible from the intermembrane space.
FGURE 19-17 Chemiosmotic model. In this simple representation of the chemiosmotic theory applied to mitochondria, electrons from $\mathrm{NADH}$ and other oxidizable substrates pass through a chain of carriers arranged asymmetrically in the inner membrane. Electron flow is accompanied by proton transfer across the membrane, producing both a chemical gradient $(\Delta \mathrm{pH})$ and an electrical gradient $(\Delta \psi)$. The inner mitochondrial membrane is impermeable to protons; protons can reenter the matrix only through proton-specific channels $\left(F_{a}\right)$. The proton-motive force that drives protons back into the matrix provides the energy for ATP synthesis, catalyzed by the $F_{1}$ complex associated with $\mathrm{F}_{\mathrm{o}}$. 
Wikstrom, PNAS 2012 (Comp. I = 3, Comp. III = 2, Comp. IV = 4)

Table 1. Conversion of measured ATP $/ 2 \mathrm{e}^{-}$ratios to proton translocation stoichiometries in respiratory chain of rat-liver mitochondria

\begin{tabular}{lcc} 
Complex & ATP $/ 2 \mathrm{e}^{-}$ & $\mathrm{H}^{+} / 2 \mathrm{e}^{-}$(efficiency, \%) \\
\hline I+ III + IV & $2.27 \pm 0.08$ & $8.32(92 \%)$ \\
III + IV & $1.48 \pm 0.04$ & $5.43(91 \%)$ \\
III & $0.49 \pm 0.02$ & $1.80(90 \%)$ \\
IV & $0.98 \pm 0.09$ & $3.59(90 \%)$ \\
I (I + III + IV minus III + IV) & 0.79 & $2.90(97 \%)$ \\
I (I+ III + IV minus III minus IV) & 0.80 & $2.90(97 \%)$ \\
\hline
\end{tabular}

The ATP $/ 2 \mathrm{e}^{-}$ratios are from Hinkle et al. (20) for rat-liver mitochondria oxidizing $\beta$-OH-butyrate $(\mathrm{I}+\mathrm{III}+\mathrm{IV})$ or succinate $(\mathrm{III}+\mathrm{IV})$ by $\mathrm{O}_{2}$, succinate by ferricyanide (III), or TMPD (+ascorbate) by $\mathrm{O}_{2}$ (IV). The $\mathrm{H}^{+} / 2 \mathrm{e}$ ratios are derived from the ATP $/ 2 \mathrm{e}$ ratio using Eq. 4 and a value of 3.67 for the $\mathrm{H}^{+}$/ATP ratio. Per cent efficiency is reported for the assumption that the effective mechanistic $\mathrm{H}^{+} / 2 \mathrm{e}^{-}$stoichiometries are 3,2 , and 4 , respectively, for complexes I, III, and IV (i.e., 9 for I III + IV and 6 for III + IV). The two ATP $/ 2 \mathrm{e}$ ratios for complex I are derived from the measured ratios, as indicated.

Wikstrom, Chem Rev 2015 (Comp. I = 3-4, Comp. III = 4, Comp. IV = 2)

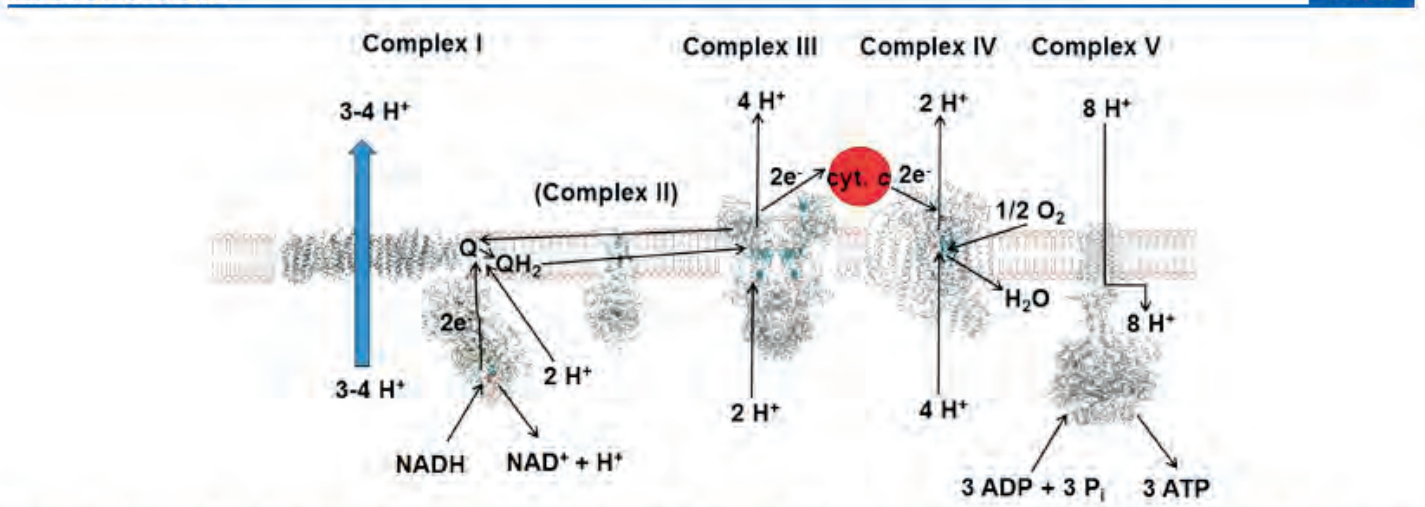

Figure 1. Respiratory chain and ATP synthase. The respiratory chain is depicted in a phospholipid membrane, as it is found in most mitochondria and in many bacteria. ATP synthase is shown to translocate 8 protons per 3 synthesized ATP molecules, as observed in animal mitochondria 
The ways in which the number of protons are transferred/cycled are also different!

Sazanov's mechanism, Nature Reviews, 2015

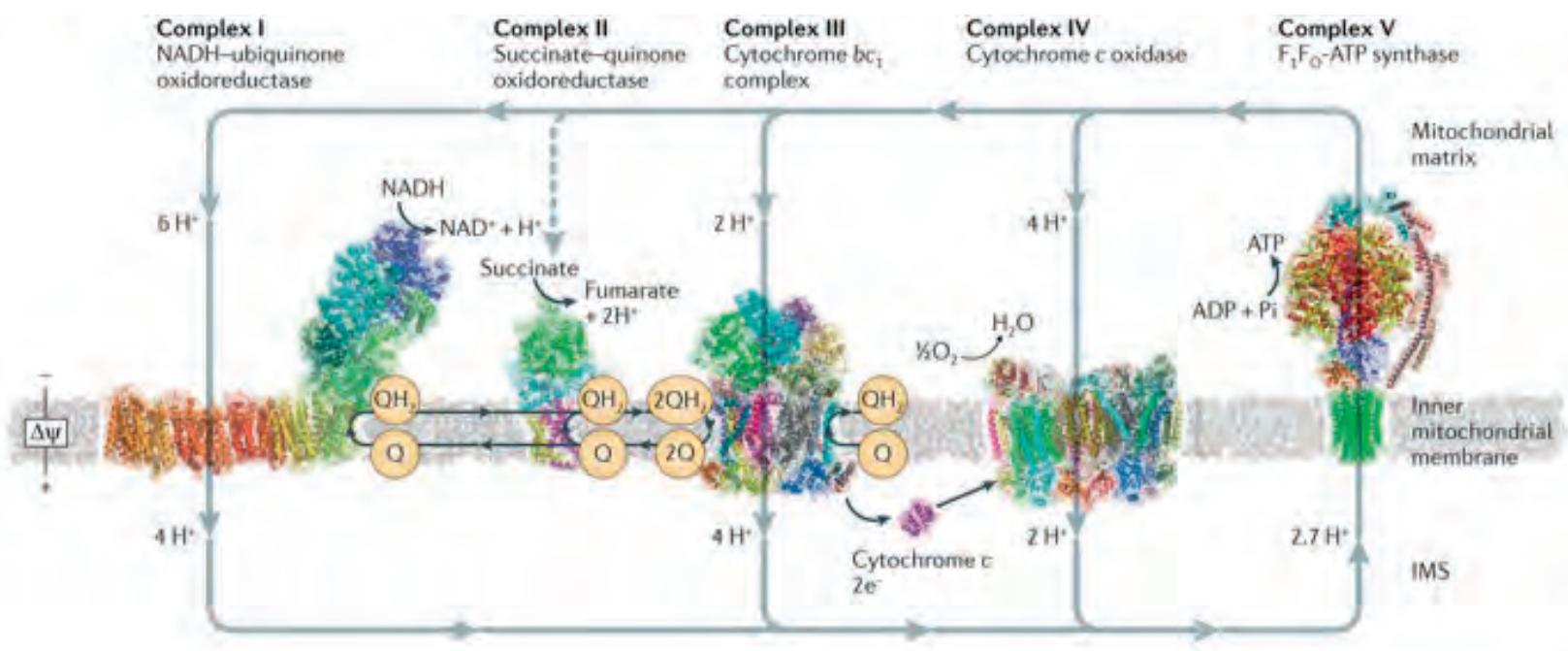

Nature Reviews | Molecular Cell Biology

Antony Crofts's mechanism (his website: https://www.life.illinois.edu/crofts/bioph354/lect8.html)

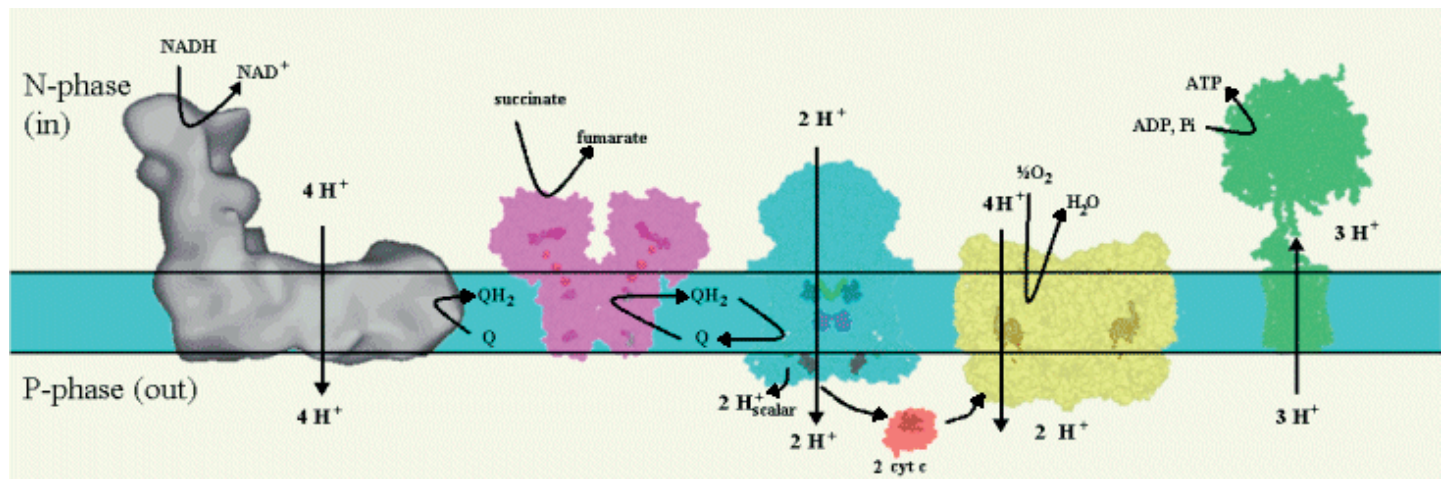

Some other researchers' publications from the Asian subcontinent $\downarrow$

Sun F et al. (Rao Zihe group) Curr. Opin. Str. Biol., 2013 (Comp. I = 4, Comp. III = 4, Comp. IV = 2)

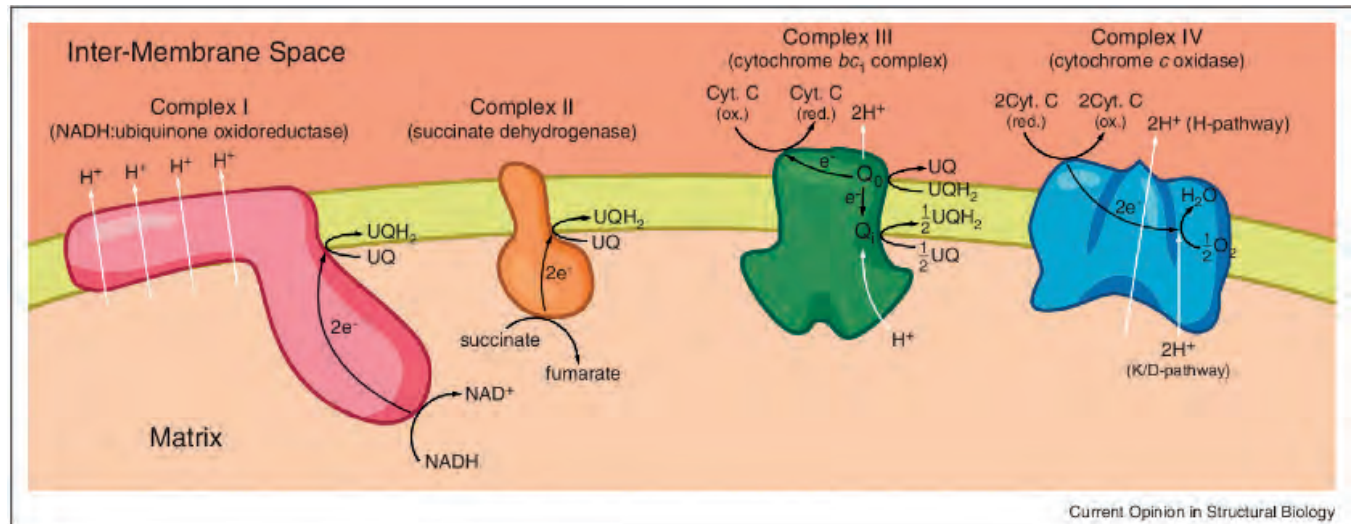


Zhao R-Z et al. (Zhi-Bin Yu group), Int. J. Mol. Med., 2019 (Comp. I = 2, Comp. III = 4, Comp. IV = 4)

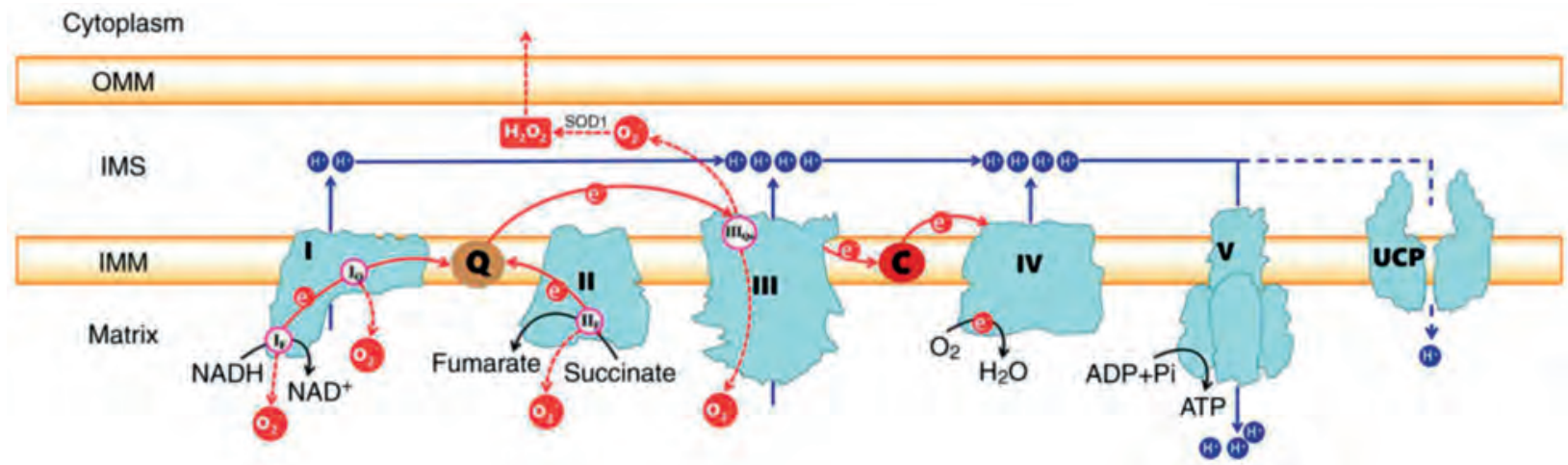

Figure 1 - Generation of electron leaks and proton leaks in the electron transport chain. Electrons derived from oxidizable substrates are passed through CI/III/IV or CII/III/IV in an exergonic process that drives the proton pumping into the IMS of CI, CIII and CIV. The energy of the proton gradient drives the ATP synthesis of CV or can be consumed by UCPs. The sites of superoxide production in each complex are also indicated, including sites IF and IQ in CI, sites IIF in CII and site IIIQo in CIII. The O -2 released into the IMS by site IIIQo can be converted into $\mathrm{H} 2 \mathrm{O} 2$ in a reaction catalyzed by superoxide dismutase 1 and $\mathrm{H} 2 \mathrm{O} 2$ then may diffuse into the cytoplasm.

Consensus formation efforts in recent times in the western hemisphere $\downarrow$

Olivier Biner et al., Chimia, 2018 (Comp. I = 4, Comp. III = 2, Comp. IV = 4)

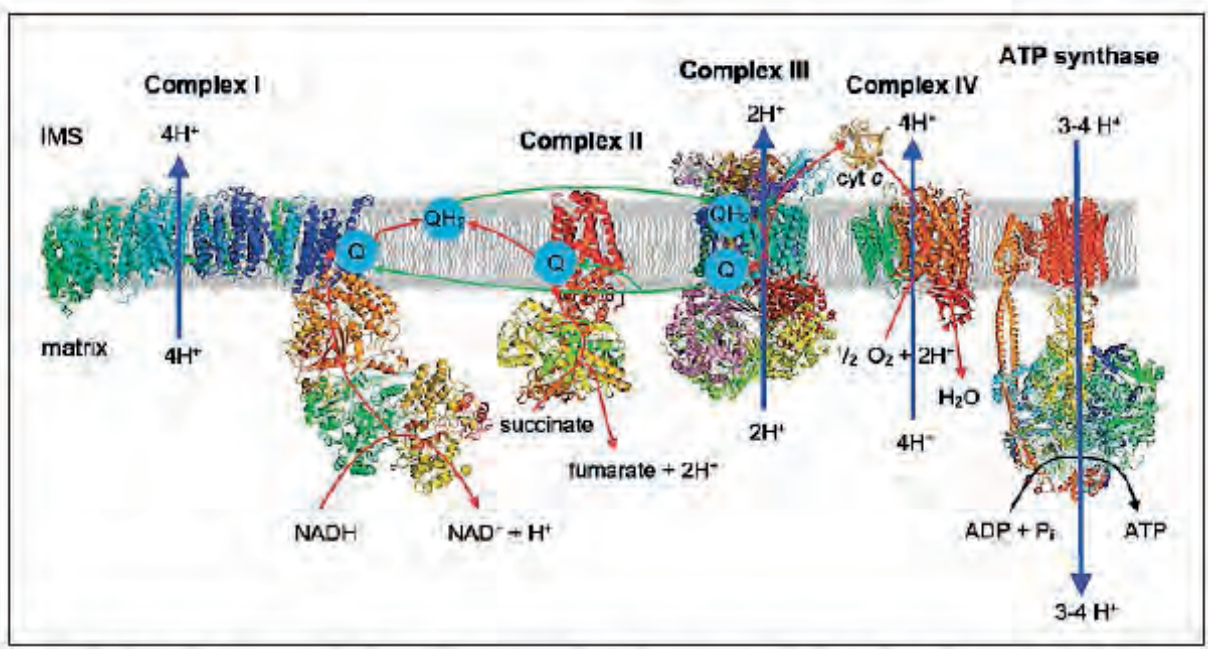

Fig. 1. Schematic representation of the respiratory chain in a mitochondrion. Complex I (PDB: $4 \mathrm{WZ7})$ oxidizes $\mathrm{NADH}$ to $\mathrm{NAD}+$ to reduce ubiquinone $(\mathrm{Q})$ to ubiquinol $\left(\mathrm{QH}_{2}\right)$. The electron transfer is coupled to the transport of four protons from the mitochondrial matrix to the inner membrane space (IMS). Complex II (PDB: 2WDV) oxidizes succinate to fumarate and reduces Q without proton translocation. The electrons are then transferred from $\mathrm{QH}_{2}$ to cytochrome $c$ via complex III accompanied by the translocation of two protons. Finally, four molecules of cytochrome $c$ are used to reduce oxygen to water in complex IV coupled to the transport of four protons. Overall, a total of ten protons are translocated across the mitochondrial membrane per NADH oxidized. The electrochemical proton gradient is dissipated by the ATP synthase to generate ATP. Electron and proton transfer processes are depicted with red and blue arrows, respectively. 
Lewis MT - Kasper JD - Bazil JN - Frizbee JC - Wiseman RW, Int. J. Mol. Sci., 2019 (Comp. I = 4, Comp. III = 2, Comp. IV =4)

\section{INTERMEMBRANE SPACE}

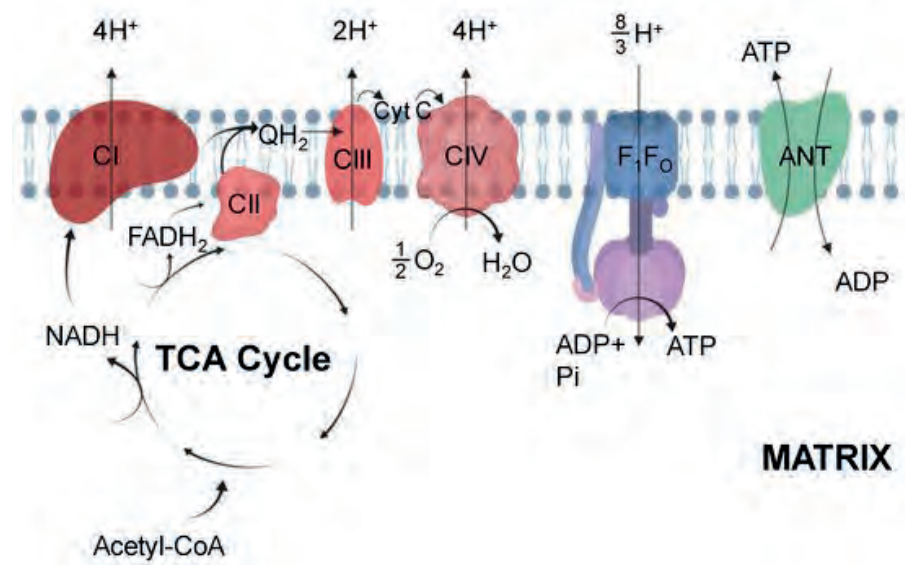

Same status prevails in chloroplast ETC-CRAS!!

Quinone pumps protons, PS II is not a proton pump!

https://bio.libretexts.org/Bookshelves/Biochemistry/Book\%3A_Biochemistry_Free_For_All_(Ahern\%2C_Rajagopa $1 \% 2 \mathrm{C}$ _and_Tan)/05\%3A_Energy/5.03\%3A_Energy_-_Photophosphorylation

\section{Chloroplast Stroma}

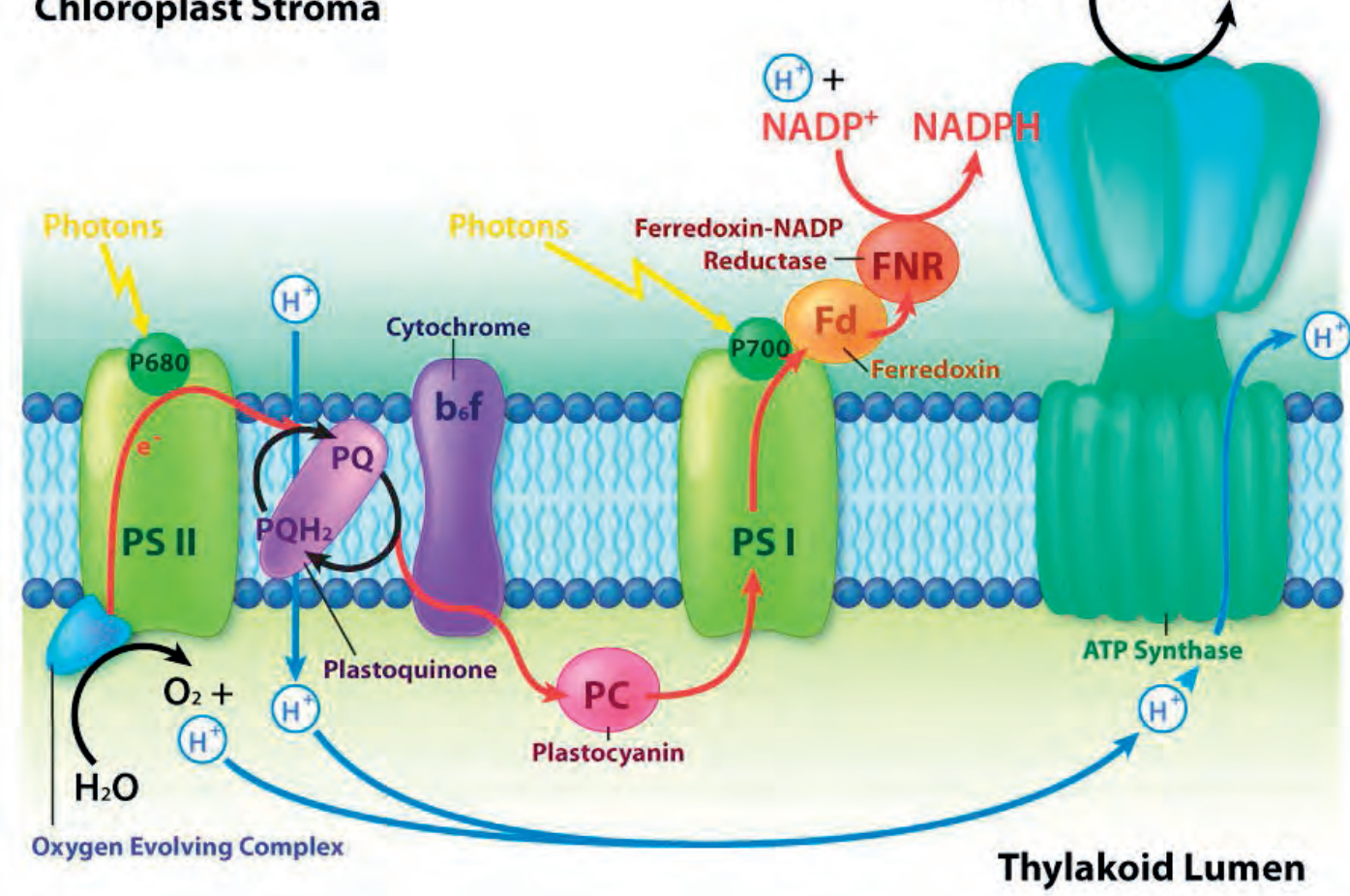


Cyt. $b_{6}$ f pumps protons with quinones, PS II is a partial proton pump!

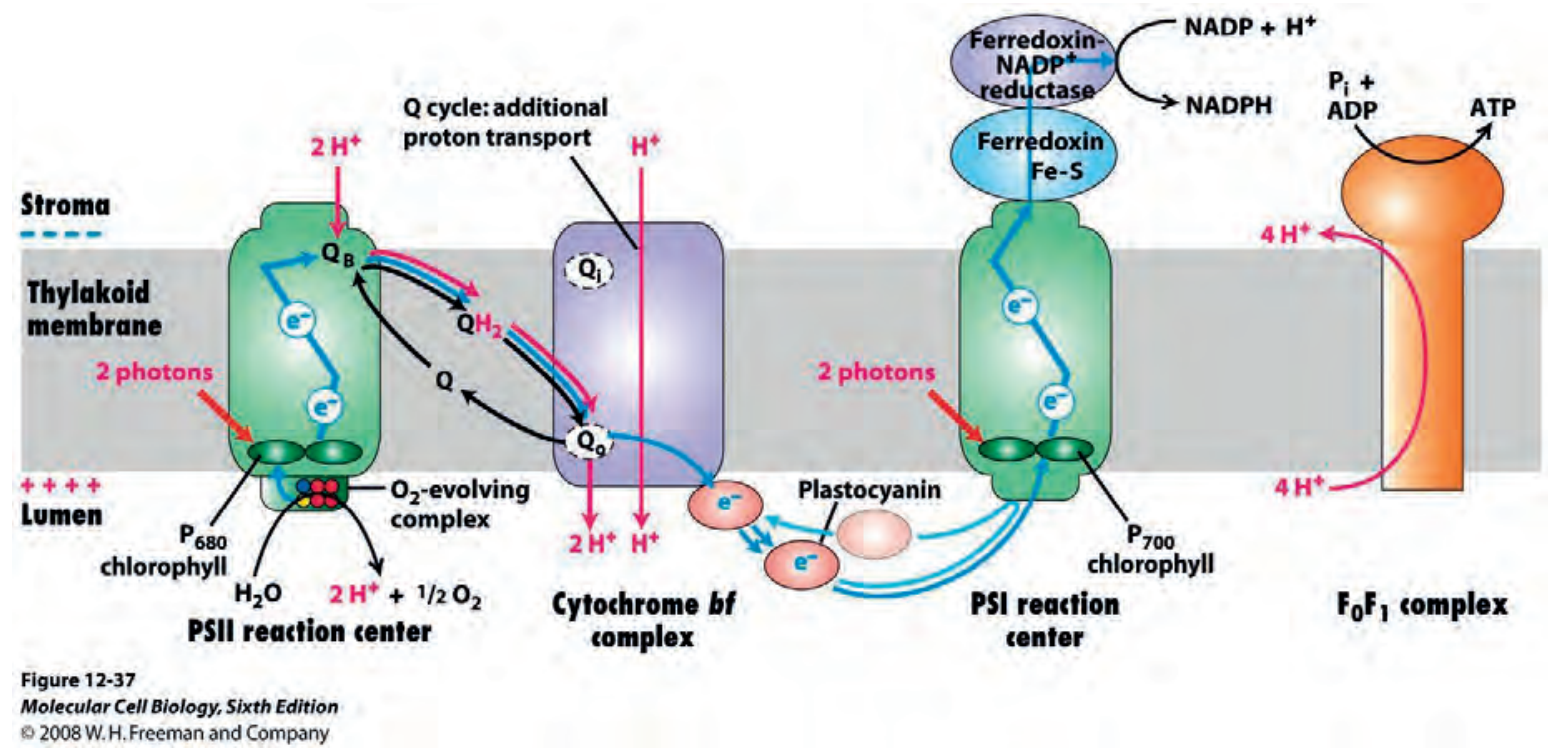

Both PS II and Cyt. $b_{6}$ f pump protons!

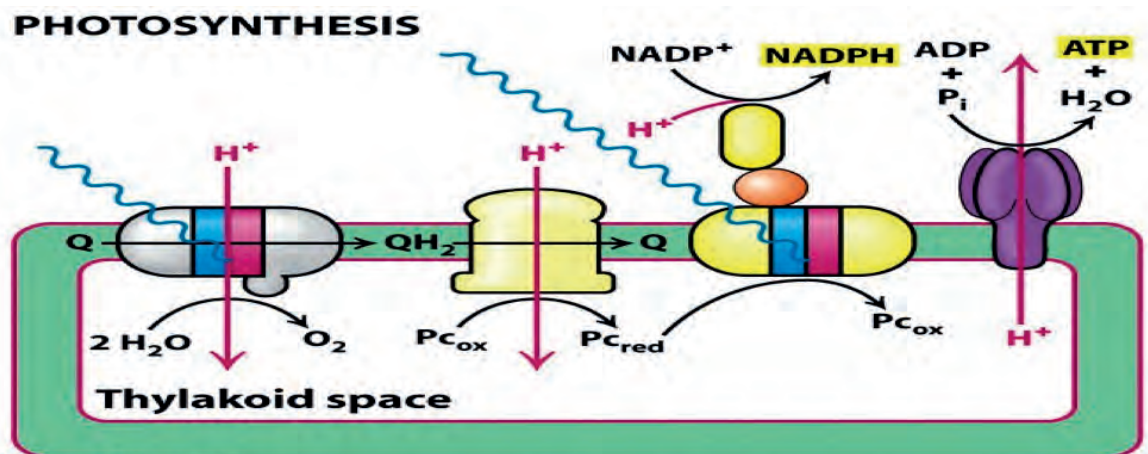

\section{Stroma}

OXIDATIVE PHOSPHORYLATION

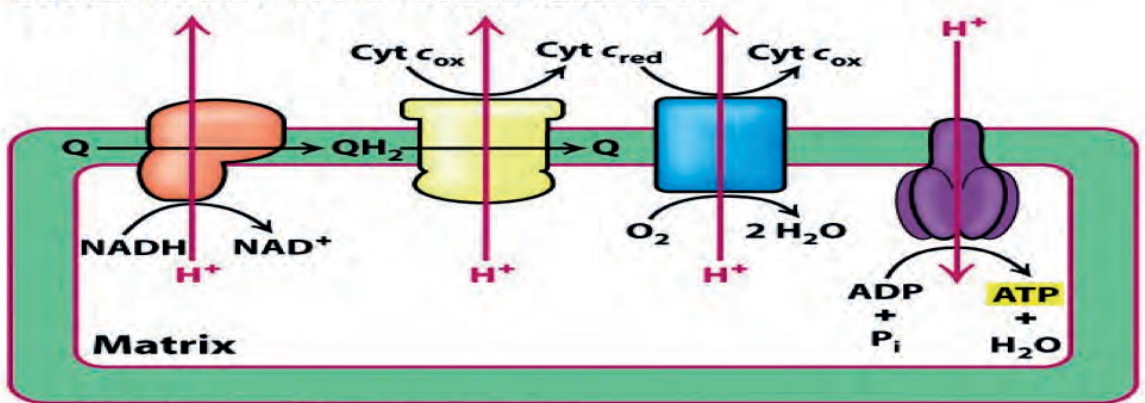

\section{Intermembrame space}

\section{Figure 19-25}

Biochemistry, Sixth Edition

(0) 2007 W. H. Freeman and Company 


\title{
Item 2: False attributions on lack of citations
}

In both the papers of KMM that PJS cites, KMM had critiqued the inferences drawn from data from duly cited

reputed sources of textbooks and reviews.

The first paper's

\section{Aerobic Respiration: Criticism of the Proton-centric Explanation Involving Rotary Adenosine Triphosphate Synthesis, Chemiosmosis Principle, Proton Pumps and Electron Transport Chain}

\author{
Biochemistry Insights \\ Volume 11: 1-23 \\ C The Author(s) 2018 \\ Article reuse guidelines: \\ sagepub.com/joumals-permissions \\ DOl: $10.1177 / 1178626418818442$ \\ (SSAGE
}

\author{
Kelath Murali Manoj \\ Satyamjayatu: The Science \& Ethics Foundation, Kulappully, Shoranur, India.
}

very first page-

the primary drive for ATP-synthesis. Since 1980s to till date, chemiosmosis or proton-centric coupling became the mainstay explanation for $\mathrm{mOxPhos}$ in leading reviews ${ }^{16,17}$ and textbooks. ${ }^{1-3}$ This acclaimed explanation comprises of the fol-

\section{REFERENCES}

1. Lehninger AL, Nelson DL, Cox M. Principles of Biochemistry. London, England: Palgrave Macmillan; 2004.

2. Berg JM, Tymoczko JL, Stryer L. Biochemistry. 5th ed. New York, NY: W. H. Freeman; 2002.

3. Voet D, Voet JG. Biochemistry. 4th ed. Hoboken, NJ: Wiley; 2011.

16. Junge W, Nelson N. ATP synthase. Anmu Rev Biochem. 2015;84:631-657.

17. Mukherjee S, Warshel A. The FoF1 ATP synthase: from atomistic three-dimensional structure to the rotary-chemical function. Photosynthesis Res. 2017;134:1-15.

The second paper's

\section{Aerobic respiration: proof of concept for the oxygen-centric murburn perspective}

Kelath Murali Manoj ${ }^{\mathrm{a}}$ (), Abhinav Parashar ${ }^{\mathrm{b}}$ (), Vivian David Jacob ${ }^{\mathrm{c}}$ and Surjith Ramasamy ${ }^{\mathrm{d}}$

${ }^{a}$ Satyamjayatu: The Science and Ethics Foundation, Palakkad, Kerala, India; 'Department of Biotechnology, Vignan's Foundation for Science, Technology \& Research, Vadlamudi, Guntur, Andhra Pradesh, India; 'Bioculer, Kottayam, Kerala, India; 'Department of Biotechnology, Indian Institute of Technology Guwahati, Guwahati, Assam, India 
first and second pages

Tve oxygen species (DROS, a perceived hazard/waste). The long-standing mechanistic explanation for cellular respiration

or mitochondrial oxidative phosphorylation (mOxPhos), as originally proposed and advocated in biochemistry textbooks and recent reviews (Berg, Tymocko, \& Stryer, 2002; Boyer, 1997; Junge \& Nelson, 2015; Lehninger, Nelson, \& Cox, 2004; Mitchell, 1961; Mukherjee \& Warshel, 2017; Voet \& Voet, 2011), solicits an elaborate 'proton-centric' dynamic scheme involving 'Rotary ATP-synthesis - Chemiosmosis principle Proton pumps - Electron Transport Chain (ETC)' (henceforth abbreviated RCPE). Several seasoned researchers have doubted many aspects of the RCPE paradigm, even after the RCPE proposal was recognized with Nobels (Berden, 2003; Ling, 1981; Nałẹcz, 1986; Nath, 2010; Slater, 1987; Wainio, 1985; Williams, 1979). Also, recent crystal structures of mam-

\section{Item 3: Here is the content from Voet textbook that we quoted to critique the energetic non-feasibility.}

Given that proton pumping requires $20-22 \mathrm{~kJ} / \mathrm{mol}$ and heterolysis of water requires $\sim 79 \mathrm{~kJ} / \mathrm{mol}$, as per all the texts, our quantitative analysis of the failure of CRAS is accurate!

\footnotetext{
830 Chapter 22. Electron Transport and Oxidative Phosphorylation

Complex I catalyzes oxidation of NADH by $\mathrm{CoQ}$ :

$\mathrm{NADH}+\mathrm{CoQ}$ (oxidized) $\longrightarrow$

This redox reaction does not release sufficient free energy to synthesize ATP; it functions only to inject the electrons from $\mathrm{FADH}_{2}$ into the electron-transport chain.
} 


\section{Item 4: The data on binding constants of Complex V that PJS disclaimed quoting that the relevant texts did not have this content.}

Table 4. Compilation of equilibrium and rate terms for the physiological functioning of Complex V.

\begin{tabular}{|c|c|c|c|c|c|c|}
\hline No. & Term & Unit & \multicolumn{2}{|c|}{ ATP synthesis } & \multicolumn{2}{|c|}{ ATP hydrolysis } \\
\hline 1 & Concentration & $M$ & $\begin{array}{l}\text { ADP } \\
\sim 10^{-4}\end{array}$ & $\begin{array}{c}\mathrm{Pi} \\
\sim 10^{-2}\end{array}$ & $\frac{\text { ATP }}{<10^{-3}}$ & $\begin{array}{l}\mathrm{H}_{2} \mathrm{O} \\
>10^{1}\end{array}$ \\
\hline 2 & Affinity, $K_{\mathrm{d}}$ & $\mathrm{M}$ & $\approx 10^{-5}$ & $>10^{-2}$ & $\leq 100$ & - \\
\hline 3 & $a k_{\text {off }}$ & $5^{-1}$ & $\sim 10^{3}$ & $\approx 10^{6}$ & $\leq 10^{-4}$ & - \\
\hline 4 & bActivity & - & $\approx 10^{1}$ & $<10^{\circ}$ & $>10^{9}$ & $\sim 10^{\circ}$ \\
\hline 5 & cRate index & - & $<10^{1}$ & & $\sim 10^{9}$ & \\
\hline
\end{tabular}

The data is duly given in Lehninger Text, as highlighted below.

Kinetic studies of the initial rates of ATP synthesis and hydrolysis confirm the conclusion that $\Delta G^{\prime \circ}$ for ATP synthesis on the enzyme is near zero. From the measured rates of hydrolysis $\left(k_{1}=10 \mathrm{~s}^{-1}\right)$ and synthesis $\left(k_{-1}=24 \mathrm{~s}^{-1}\right)$, the calculated equilibrium constant for the reaction

$$
\text { Enz-ATP } \rightleftharpoons \operatorname{Enz}-\left(\mathrm{ADP}+\mathrm{P}_{1}\right)
$$

is

$$
K_{\mathrm{eq}}^{\prime}=\frac{k_{-1}}{k_{1}}=\frac{24 \mathrm{~s}^{-1}}{10 \mathrm{~s}^{-1}}=2.4
$$

From this $K_{\text {eq }}^{\prime}$, the calculated apparent $\Delta G^{\prime \circ}$ is close to zero. This is much different from the $K_{\mathrm{eq}}^{\prime}$ of about $10^{5}$ $\left(\Delta G^{\prime \circ}=-30.5 \mathrm{~kJ} / \mathrm{mol}\right)$ for the hydrolysis of ATP free in solution (not on the enzyme surface).

What accounts for the huge difference? ATP synthase stabilizes ATP relative to $\mathrm{ADP}+\mathrm{P}_{\mathrm{i}}$ by binding ATP more tightly, releasing enough energy to counterbalance the cost of making ATP. Careful measurements of the binding constants show that $\mathrm{F}_{\mathrm{o}} \mathrm{F}_{1}$ binds ATP with very high affinity $\left(K_{\mathrm{d}} \leq 10^{-12} \mathrm{M}\right)$ and $\mathrm{ADP}$ with much lower affinity $\left(K_{\mathrm{d}}=10^{-5} \mathrm{M}\right)$. The difference in $K_{\mathrm{d}}$ corresponds to a difference of about $40 \mathrm{~kJ} / \mathrm{mol}$ in binding energy, and this binding energy drives the equilibrium toward formation of the product ATP. 